PRECIPITATION OF MERCURy BY COPPER.

\begin{tabular}{|c|c|c|c|c|c|c|c|}
\hline $\begin{array}{c}\text { No. } \\
\text { of } \\
\text { analysis. }\end{array}$ & $\begin{array}{l}\text { Time, } \\
\text { first } \\
\text { coill } \\
\text { Hrs. }\end{array}$ & $\begin{array}{c}\text { Time, } \\
\text { second } \\
\text { coill. } \\
\text { Hrs. }\end{array}$ & $\begin{array}{l}\text { Weight of } \\
\text { Hg. Grst } \\
\text { coil. } \\
\text { Gram. }\end{array}$ & $\begin{array}{l}\text { Weight of } \\
\text { Hg, second } \\
\text { coil. } \\
\text { Gran. }\end{array}$ & $\begin{array}{l}\text { Total } \\
\text { Hg } \\
\text { found. } \\
\text { Gram. }\end{array}$ & $\begin{array}{c}\text { Total } \\
\text { Hg } \\
\text { takell. } \\
\text { Gram. }\end{array}$ & $\begin{array}{l}\text { Error. } \\
\text { Gram. }\end{array}$ \\
\hline I & 2 & 2 & 0.0297 & 0.0028 & 0.0325 & 0.0332 & -0.0007 \\
\hline 2 & 3 & 2 & 0.0308 & 0.0015 & 0.0323 & 0.0332 & -0.0009 \\
\hline 3 & 4 & 2 & $0.03 \mathrm{II}$ & 0.0014 & 0.0325 & 0.0332 & -0.0007 \\
\hline 4 & 5 & 2 & 0.0320 & 0.0006 & 0.0326 & 0.0332 & -0.0006 \\
\hline 5 & 6 & 2 & 0.0318 & 0.0009 & 0.0327 & 0.0332 & -0.0005 \\
\hline 6 & 7 & 2 & 0.0326 & 0.0003 & 0.0329 & 0.0332 & -0.0003 \\
\hline 7 & 18 & 2 & 0.0328 & 0.0003 & $0.03 .3 \mathrm{I}$ & 0.0332 & -0.0001 \\
\hline 8 & I 8 & 2 & 0.0329 & $0.000 \mathrm{I}$ & 0.0330 & 0.0332 & -0.0002 \\
\hline
\end{tabular}

This table shows that during two hours 0.9 of the mercury had been precipitated. The introduction of a second fresh coil for two hours more took out four-fifths of the remaining mercury, while leaving the first coil in the solution for the same additional time precipitated half of this residue; these data demonstrate the efficiency of the second coil. Experiment, kindly made for us by Mr. G. F. Behr, Jr., showed that amalgamated copper has essentially the same solution-tension as pure copper, hence the more tardy action of the already analgamated copper was due merely to the hindering effect of the film of liquid metal in which the copper must dissolve before ionizing. In seven hours, even a single coil precipitated all but 0.6 milligram of mercury, the removal of this last portion requiring more than double the time. The best results would probably be obtained by allowing the first coil to remain four of five hours in the solution, and the second coil to remain there for twenty hours. Stirring would probably accelerate greatly the leposition, and this might be most readily effected by causing the copper coil to rotate. The efficiency of rotating cathodes and anorles in electrolysis has been demonstrated by several experimenters, and this is a parallel case.

HARTARD CNIVERSTT,

December, 1903 .

\title{
SOME PROPERTIES OF PHENYL ETHER.
}

BY AIFRHI N. COOK.

Received fanunty 4, 2904.

Althovan many derivatives of phenyl ether have been prepared, the properties of the mother substance have not heretofore 
received careful attention. The following properties have been carefully noted by the author.

Solubility.-It is soluble in all ordinary organic solvents. 4.97 parts of the ether are soluble in 100 parts of 87 per cent. alcohol at $-10^{\circ}$. At higher temperatures it is very much more soluble. It is soluble in a strong solution of sodium phenolate in water, but is precipitated again on adding considerable water. Water, which has been shaken with phenyl ether, has a strong odor of the substance, and the water obtained from distilling with steam smells very strongly of the substance. When it is allowed to stand and cool it deposits long fiber-like crystals, which extend entirely across the containing vessel. It seems, therefore, to be slightly soluble in water, although it has heretofore been considered insoluble in that menstruum.

Boiling- and Melting-points.-The product obtained from distilling aluminum phenolate was washed with caustic soda solution to remove any traces of phenol. It was then distilled seventeen times, discarding the first and last portions each time, crystallized from itself twelve times and from alcohol five times. It then had a perfectly constant boiling-point. The average of several trials which did not vary from each other more than a few hundredths was $258.97^{\circ} \mathrm{C}$. after making all corrections. The thermometer was calibrated with water, naphthalene and benzophenone, and required but a small correction. The boiling-point has heretofore been reported at $246^{\circ}$ to $254^{\circ}$. These numbers were presumably uncorrected.

The melting-point of the substance, purified as above, was found to be $26.9^{\circ}-27^{\circ} \mathrm{C}$., using a standard thermometer graduated in tenths. On crystallizing again from alcohol several times and distilling with steam, the melting-point was found to be exactly the same.

Crystallization.-Phenyl ether crystallizes from alcohol in large, thin, white plates. On cooling, per se, large prismatic crystals were formed, of which the accompanying figure is a fair representative. Some of the crystals lacked one or more faces, but all were hexagonal prisms, apparently belonging to the monoclinic system. The measurement of a specimen gave: Length, I cm.; width, $3.5 \mathrm{~mm}$; thickness, I mm. Two other experimenters have stated that the presence of a very small amount of a foreign sub- 
stance prevents it from solidifying, but I do not find that this is

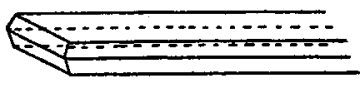

Crystal of phenyl ether.

true of phenyl ether any more than with liquids ordinarily. This would also be contrary to now well-known physical-chemical laws.

Volatility.-0.6 gram when heated in a watch-glass on the water-bath lost nearly $0.2 \mathrm{gram}$ in twenty minutes. A small quantity exposed in a beaker at room temperature gradually lost in weight and in six months had almost entirely disappeared. When dried over sulphuric acid the solid ether volatilizes and the acid becomes very much blackened.

Specific Gravity.-The following table gives the specific gravity of the liquid phenyl ether at different temperatures, determined with the Westphal balance.

Tempe

$$
\begin{array}{r}
\text { Specific } \\
\text { gravity. } \\
1.0535 \\
1.0582 \\
1.0629 \\
1.0677 \\
1.0724 \\
1.0773
\end{array}
$$

Difference.
0.0047
0.0047
0.0048
0.0047
0.0049
$\ldots . .$.

The specific gravity of the liquid ether, determined with the pycnometer at $20^{\circ}$, was 1.0728 , and of a specimen that had solidified, I.I 508 at $10.75^{\circ} \mathrm{C}$.

Other Properties.-It is oily in character. It has no taste at first, but after a few moments it gives a burning sensation to the tongue and lips. When prepared from aluminum phenolate it was very fluorescent until thoroughly purified. When purified by distilling with steam it is not altered in the light, otherwise it gradually assumed a deep yellow color.

It burns with a smoky flame, liberating a large amount of soot. As has previously been noticed, it has the odor of geraniums, but when hot it has a marked sweetish odor. A teaspoonful administered to a full-grown cat caused frothing at the mouth and considerable discomfort apparently in the throat and stomach, probably due to a burning sensation, but in half an hour the animal was apparently in an entirely normal condition.

MORNINGSIDE COLLEGE,

Srovx City, iA.,

September $2 I$, IgO3. 